\title{
Effects of pricking, sun-drying and sieving on Ginger (Zingiber officinale Roscoe) colour and powder
}

\author{
OKAFOR G.I. ${ }^{1 *}$ and OKAFOR J.N.C. ${ }^{2}$ \\ ${ }^{1}$ Department of Food Science and Technology, University of Nigeria, Nsukka. Enugu State, Nigeria \\ ${ }^{2}$ Federal Institute of Industrial Research, Oshodi, Lagos, Nigeria. \\ * Address for correspondence: Email : giokafor@unn-edu.net
}

ABSTRACT

\begin{abstract}
The effect of pricking, sun drying and sieving on the color retention of Nigerian yellow bark ginger were investigated. The exterior and interior surface of fresh, pricked and sun dried medium sized Nigerian ginger rhizomes (Tafin giwa) were analysed for colour variation. The colour values of the exterior surface of fresh ginger were, $L^{*} 59.8 \pm 2.6 ; a^{*}$ $3.7 \pm 0.7 ; b^{*} 16.9 \pm 0.75$, while the pulp $L^{*} 74.0 \pm 0.96 ; a^{*}$ $6.20 .5 \mathrm{~b}^{*} 32.8 \pm 1.28$. The interior colour of fresh ginger surface was $24 \%$ lighter than the skin surface colour. Drying decreased the external surface colour by $12.5 \%$,
\end{abstract}

\section{INTRODUCTION}

$\mathrm{G}$ inger is the rhizome of Zingiber officinale, with an agreeable aroma and pungent taste (HMSO, 1993). It is one of the most important articles of trade in the world spice market, where it is found fresh, dehydrated, preserved powdered and other forms. Though Nigeria is among the World's largest producers of ginger, it has been observed that the quality of its dried ginger has been declining, due to low level of mechanization of ginger production and processing (Onu and Okafor, 2002), as a result Nigerian ginger attracts the cheapest price in the world market (Ekundayo et. al., 1988). This tendency has attracted the attention of many players in the International market, with remarks that the quality of Nigerian ginger should be improved.

The colour of ginger has been described as even and light buff (Kroschwitz and Howe-Grant, 1994). According to Uhl (2000), ginger's flavour and colour vary with its origin and harvesting, pricking darkened the interior surface of ginger by $7.2 \%$ and $2.6 \%$ respectively for black and gray backgrounds respectively, while sieving was found to lighten the obtained powder up to $3.7 \%$ and $2.9 \%$ for whole and pricked dried powdered samples. Drying decreased the "b" values (yellowness) by $32 \%$ compared to the "b" values of fresh samples, and a range of $42-87 \%$ also decreased "a" values.

Keywords: Ginger, colour, powder, yellow bark, pricking, drying, sieving 
This research work was conceived to establish the colour of Nigerian Yellow bark ginger and study the effects of sun drying on black and gray surfaces, pricking and sieving of the obtained ginger powder on its colour to enhance its consumer acceptance.

\section{MATERIALS AND METHODS Raw materials}

The fresh ginger rhizomes used were Nigerian bold yellow ginger (Tafin giwa) purchased at Oshodi market in Lagos, Nigeria. Washing and sorting

The rhizomes were washed to remove the adhering sand/mud, by steeping in water overnight (15hours) at room temperature $28 \pm 2$, which loosens the mud, before washing under running water till the rhizomes were clean. The rotten rhizomes were removed once spotted during the cleaning operation.

\section{Grading}

The washed ginger rhizomes were graded according to uniform sizes big, medium and small, by using a manual ginger grader (Okafor, 2002). The medium sized rhizomes were selected for the study to ensure uniform drying rates.

\section{Pricking}

A table fork was used to prick both sides of the ginger rhizomes.

\section{Drying Studies}

The prepared ginger samples (whole and pricked) were sun dried on black polyethylene sheet of low density. Gray concrete surface covered with a transparent polypropylene sheet was used as control. The ginger rhizomes were spread uniformly to enhance drying, and weight reduction also taken as moisture loss, was monitored at the end of each day using Mettler PE 3000 Top Loading Digital Balance. The surface temperature of the drying materials was monitored with the aid of a digital thermometer. The maximum temperatures recorded in the course of the experiment are $55^{\circ} \mathrm{C}$ and $52.6^{\circ} \mathrm{C}$ respectively for black and gray backgrounds respectively. Though there were temperature fluctuations due to other climatic factors, the difference in temperature between the two drying backgrounds, fell within $3-7^{\circ} \mathrm{C}$ range.

\section{Preparation of Ginger Powder}

The dried ginger samples (pricked and whole) dried on gray and black surfaces were milled separately using Sweema dry miller (India), after milling the powder was sieved to a particle size of 295 microns using mesh No 50 and packed in a transparent polypropylene sachet, sealed and kept for estimation of colour.

\section{Colour Measurement}

Colour readings in the CIE L* $a^{*} b^{*}$ space were measured with UV - visible recording Minolta Spectrophotometer Chroma Meter3500d and analyzed with AC4806 Spectro Minolta CM-3500d software. The exterior colour of fresh ginger was taken after cleaning the rhizome from dirt by washing, while the interior colour of fresh ginger were read from the rhizomes cut vertically with a sharp knife. The surface and internal colour of whole and pricked ginger, sun dried on gray and black backgrounds as well as their powders were equally taken. The standards consist of a white tube made of barium sulphate (100\% whiteness) used as a perfect white object for setting an instrument with the illuminant and a transparent polypropylene material in which the obtained powders were packed. The colour of the low-density black polyethylene sheet, which served as the black background along with the gray concrete surface covered with a transparent polypropylene sheet were equally measured (Table 1 ). The readings were taken in triplicate. 


\section{RESULTS AND DISCUSSION}

The colours of black and gray sun drying surfaces are presented in Table 1. The black surface was found to be $144 \%$ darker than the gray surface. According to Parker (1983), the black body is an ideal radiator, which at any specified temperature, emits in each part of the electromagnetic spectrum the maximum energy obtainable per unit time from any radiator due to its temperature alone. It also absorbs all the energy, which falls upon it, contrary to gray surface. Whole and pricked medium sized ginger rhizomes subjected to sun drying on black and gray backgrounds, took 8 and 9 days on black and gray surfaces respectively to reach a final yield to $15 \%$, while whole rhizomes took 11 and 14 days to attain the same constant yield on black and gray surfaces respectively (Okafor, 2002). The increased rate of moisture loss from both the pricked and whole rhizomes dried on black background may have affected pigment structures in the samples as indicated in the results below. Colour readings of the external surface of fresh, whole and pricked ginger, dried on black and gray surfaces. The colours of medium sized Nigerian whole and pricked yellow bark ginger, sun dried on gray and black surfaces are presented in Table 2 .

The results in Table 2 revealed that sun drying darkened the skin colour of both whole and pricked dried ginger. Whole dried rhizomes were found to be $12.5 \%$ and $12.88 \%$ darker than the surface colour of fresh rhizomes, for black and gray surfaces respectively, while pricked samples were $10.87 \%$ and $10.7 \%$ darker than the fresh samples for black and gray surfaces respectively. Implying that the skin colours of prick dried samples is lighter than the external colour of whole dried samples. The values of $a^{*}$ and $b^{*}$ remained almost unchanged in all the samples.
The effect of pricking and drying surface on the pulp (internal surface) colour of dried ginger is displayed on Table 3. The L value of the internal colour of whole samples dried on black surface was $11.76 \%$ lighter than the control (fresh interior surface of ginger), whereas the interior colour of whole samples dried on gray background was 7.3\% lighter than the control. Pricking resulted in a darker interior compared to the whole dried samples, for both drying surfaces. This is as a result of the enzymatic reactions on the wounded parts with dark patches. However the L value of pricked samples dried on black surface was found to be $4.65 \%$ darker than pricked samples dried on gray surface. Drying decreased the " $b$ " values (yellowness) by $32 \%$ compared to the " $b$ " values of fresh samples, and "a" values were also decreased by a range of $42-87 \%$.

Table 4 presents the colours of sieved and unsieved powdered ginger. A critical assessment of the powder showed that sieving slightly improved the colour of the obtained powder, it made the samples appear greener shown by lower "a" values for both powder obtained from pricked and whole samples. The unsieved samples had lower values of "L", implying that the powder appeared darker than the sieved samples.

This may probably be attributed to the presence of high levels of milled ginger skin in the powder. Pricked powdered samples were found to be slightly darker and less green than the whole dried powdered samples. Drying surface seams to have no effect on powder colour.

\section{CONCLUSION}

It is evident from this study that sun drying darkened the external surface of ginger on both drying surfaces, sieving improved the colour of the powders, while pricking produced an appealing colour, which is slightly darker than whole dried and powdered samples. 


\section{REFERENCES}

Adeyemi, S.K and Onu, L. I. (1997). Development of ginger processing machinesginger peeler. Annual Research Report, Federal Institute of Industrial Research, Oshodi, Lagos, Nigeria.

Akomas, G.E.C. and Oti, E.(1988). Developing a technology for the processing of Nigerian ginger (Zingiber Officinale Roscoe) B.O.Njoku et. al. (Eds), Proceedings of the First National Ginger Workshop Umudike, Nigeria, Shanks Int. Nig Ltd, Ebute Meta, Lagos. p 93-100

Good, H. (2006). Measure to ensure the colour stays right. HMSO British pharmacopeia, Vol. 11

Ekundayo, O., Laakso, I. and Hiltunen, R. (1988). Composition of Ginger (Zingiber officinale Roscoe) Volatile Oils from Nigeria. Flavour and Fragrance J., 3:85-90.

Kroschwitz J.I. and Howe-Grant M. (1994). Encyclopedia of Chemical Technology Vol 11 th ed. John Wiley \& Sons Inc., p. 57.

Nwandikom G.I. and Njoku B.O. (1988). Designrelated physical properties of Nigerian ginger (Zingiber Officinale roscoe) In B.O.Njoku et. al. (Eds), Proceedings of the First National Ginger Workshop Umudike, p 101-107

Okafor, G.I. (2002). Processing and utilisation of ginger: effect of processing methods on product quality, and its application in fruit and bakery products. TWAS-CSIR Postdoctoral Fellowship Research Report, CFTRI, India. p. 32
Okwuwulu, P. A., and Nnodu, E. G. (1986). The effect of age at harvesting and pre-storage chemical treatment on the shelf life of fresh ginger rhizomes. Paper presented at the 22nd Annual Conference of the Agricultural Society of Nigeria, Ahmadu Bello University, Zaria, Nigeria, 1-3 Sept, Agricultural Society of Nigeria.

Onu, L.I. and Okafor G. I. (2003). Effect of physical and chemical factor variations on the efficiency of mechanical slicing of nigerian ginger (Zingiber officinale rose). J. Food Engineering 56:43-47.

Onu, L. I. (1997). Design and fabrication of manual ginger slicing machine. Annual Research Report. Federal Institute of Industrial Research, Oshodi, Lagos, Nigeria.

Onu, L. I. (1998). Testing and characterization of mechanical slicing of ginger. Annual Research Report. Federal Institute of Industrial Research, Oshodi, Lagos, Nigeria.

Oti, E., Okwuowulu, P.A., Ohiri V.U. and Chijioke G.O. (1988) Biochemical changes in ginger (Zingiber officinale roscoe) rhizomes stored under river sand and under dry grass in pits in the humid tropics. Trop. Sci. J. 28: 87-94.

Parker S.P. (1983). McGraw Hill Encyclopedia of Physics. McGraw-Hill Inc., USA. p 83

Uhl, R.S. (2000). Handbook of spices, seasoning and flavourings. p. 113 


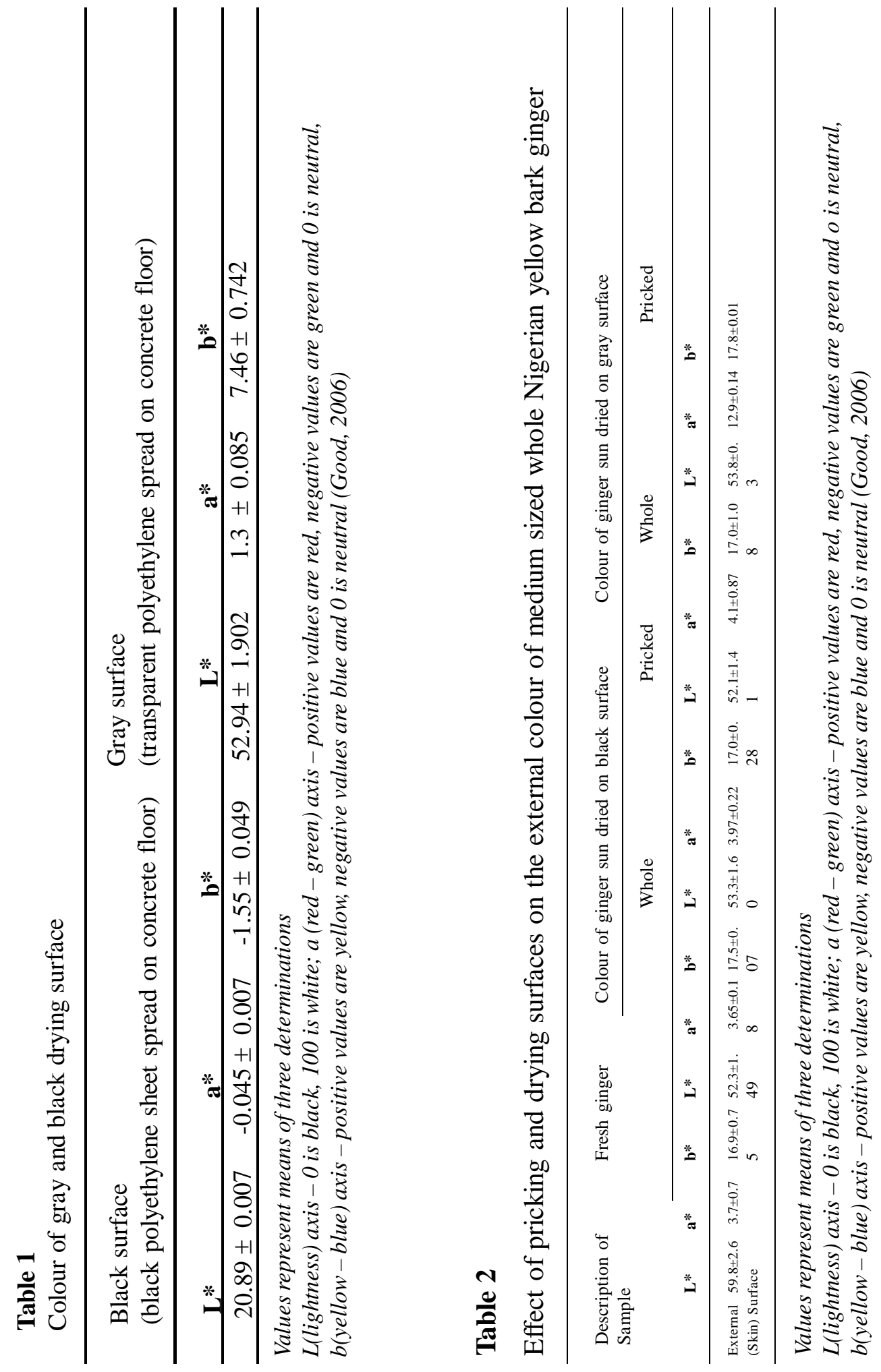


Effects of pricking, sun drying sieving on the colour of ginger.......................................................................... et al

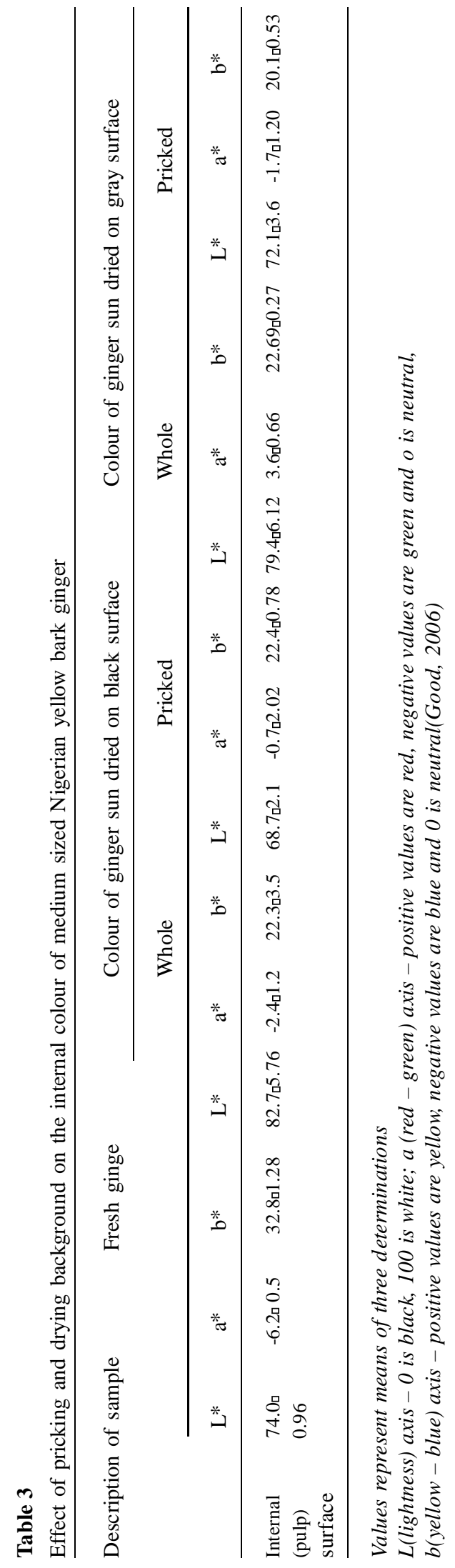

